Kansas State University Libraries

New Prairie Press

\title{
A SIMULATION STUDY OF FIELD TRIAL ANALYSIS
}

Perry Y. Jui

Follow this and additional works at: https://newprairiepress.org/agstatconference

Part of the Agriculture Commons, and the Applied Statistics Commons

\section{(c) (i) $(9)$}

This work is licensed under a Creative Commons Attribution-Noncommercial-No Derivative Works 4.0 License.

\section{Recommended Citation}

Jui, Perry Y. (1990). "A SIMULATION STUDY OF FIELD TRIAL ANALYSIS," Conference on Applied Statistics in Agriculture. https://doi.org/10.4148/2475-7772.1440

This is brought to you for free and open access by the Conferences at New Prairie Press. It has been accepted for inclusion in Conference on Applied Statistics in Agriculture by an authorized administrator of New Prairie Press. For more information, please contact cads@k-state.edu. 
A Simulation Study of Field Trial Analysis

\author{
Perry Y. Jui \\ Statistical Research Section \\ Research Program Service \\ Agriculture Canada \\ Ottawa, ontario K1A OC6 Canada
}

\title{
Abstract
}

In variety trials, lattice designs are perhaps the most popular ones used by agriculture researchers. An eight by eight lattice design in which there were 56 test cultivars and a check cultivar in each of the eight blocks, was replicated four times. A simulation was performed in which the lattice design was superimposed on two soil fertility maps, one relatively uniform (map 1) and one more heterogeneous (map 2). Ratios of soil variation to total variation (soil + error) ranging from . 1 to 1.0 were studied. The results suggest that in the present setup blocking is more effective when soil variability is small but not very effective when soil variablility is large. The relative efficiency of lattice design over randomized block design increased from 101\% to $136 \%$ as the ratio of soil to total variation varied from 0.1 to 1.0 in map 1 and ranged between $101 \%$ to $117 \%$ in map 2 . The average within replication variance of the data from check plots was close to the intra-block error for map 1 but generally slightly larger for map 2. A 30-70\% improvement in relative efficiency was found in the results after the data were adjusted for check cultivar in each block.

Key words: Lattice Design, Control Plot, Relative Efficiency. 
1. Introduction

In variety trial, especially when large number of cultivars are involved, the control of soil variation has always been a problem for research workers. A simple way which has been practised is to introduce control plots along with the testing variety Pritchard (1916), Briggs and Shebeski (1968). By adjusting the soil variability from the control plots, a better estimate of yield is expected. However, Yates (1936) recommended not to use control plot but to arrange plots in pseudo-factorial with small block size. Although many different methods of adjustment have been suggested, a general method which can apply to all situations has not been found yet. Recent research of Kempton and Howes (1981) reported that using the Papadakis method to adjust a cultivar value by its neighbouring plot values can reduce the variation of unknown sources to an extent equivalent to that by lattice square design. Unfortunately, such a method has not been developed simple enough for general usage. This paper intends to investigate whether or not adding a control or check variety at each block in a lattice design can improve the precision of the experiment.

2. Design and Simulation

First, the soil fertility contour maps were generated and value assigned to each grids according to the symbols designated. The average of 5 by 6 rectangular grids formed the basic plot value. After the two soil fertility maps were generated, the field was partitioned into blocks and plots: within each block. Eight by eight lattice design with four replications chosen from plan 10.5 from Cochran and Cox 1957 pp 430 were used. Randomization was carried out among replications, among blocks within each replication and then 
among plots within a block. The 64 entries consist of 56 testing varieties and one check variety appearing in each of the eight blocks and their values were arbitrarily assigned. Ten different sizes of random errors in proportion to the total variation (soil + error) in each replication were also generated. The ten simulated soil variation to total variation ratios were ranged between $10 \%$ to $100 \%$ at an interval of 10\%. According to cox and cochran (1955), the lattice design can be repsented by :

$$
Y_{i j k}=u+T_{i}+R_{j}+B_{i j}+e_{i j k}
$$

where $Y_{i j k}, u, T_{i}, R_{j}, B_{i j}$ and $e_{i j k}$ represent the yield, the population mean, the variety mean, the replication mean, the incomplete block and the intra-block residual error respectively. In the case of randomized complete block design, the incomplete block and the intra-block residual error terms are inseparable. Replication effect in this study is not considered to be a major concern, therefore, the soil fertility and random errors were adjusted by their replicaiton means respectively. In essence, the data were simulated based on the following model:

$$
Y_{i j k}=t_{i}+b_{j k}+e_{i j k}
$$

where $Y_{i j k}$ is the deviation of the yield of ith variety in $j$ th replication and $\mathrm{kth}$ plot from the population mean; $t_{i}$ is the mean response value of ith variety; bjk is the jth replication, kth plot soil fertility value deviated from its replication mean and $e_{i j k}$ is the deviation of random error from its replication mean.

The data obtained were analyzed according to the lattice design where the control was implemented in each block of the replication and treated as one of the testing cultivars. Another analysis was done on data from which the value of control was substracted from each of the testing cultivars within that particular incomplete block. The relative efficiency of the lattice design from both analyses was calculated by comparing the residual mean squares with that of 
the randomized complete block design. In this design, an extra information can be extracted from the control plots where the variation consist only soil variability and random errors. This variation can also be used to compare with the residual mean squares of the lattice design.

\section{Results and Discussion}

Two soil fertility maps one with simpler soil gradient (Map 1) and one with complex soil gradient (Map 2) were shown in Figure 1. The magnitude of soil variation for both map and all four replications were shown in Table 1 . The coefficients of variation ranged from 12.5 to $21.9 \%$ in map 1 whereas in map 2 the C.V. ranged from 27.3 to $41.3 \%$ which is twice of that in map 1. Such soil variabilities were noticed from many field experiments Kalamkar (1932), Wiebe (1935).

The ANOVA results of lattice design from the simulated yield data of map 1 and map 2 were shown in Tables 2 to 5 . The relative efficiency of lattice design over randomized block design is generally higher in map 1 than map 2 when soil variation is relatively larger than the random errors. However, when the soil variation is relatively smaller, little difference in relative efficiency between map 1 and map 2 was observed. The relative efficiency increased from $101 \%$ to $136 \%$ as the ratio of soil to total variation varied from 0.1 to 1.0 in map 1 and ranged between $101 \%$ to $117 \%$ in map 2. Johnson and Murphy (1943) applied lattice design to a uniformity test of oats. They reported that the gains in precision were in general agreement with variation in soil heterogeneity of the uniformity test.

It is also noticed that the mean squares of control plots were slightly larger than that of the lattice design (Table 2) when the soil variation is greater than 50 percent in Map 1. However, in Map 2 where soil was more heterogeneous, the mean 
squares of control plots were almost all greater than the error mean squares in the lattice analyses (Table 4). It is suggested that the use of lattice design in general improve the precision of the experiment.

When the data was adjusted for control plot in each block (Table 3 and Table 5), the relative efficiency is generally higher than the unadjusted (Table 2 and Table 4 ). A range of 30 - 70\% improvement was found. It is suggested that the introduction of a control plot in each block can greatly increase the precision of the experiment. Briggs and Shebeski (1968) recommended that control plot should be frequently used and the adjacent plot can be used as a good measure of the soil fertility. Gacula (1978) has introduced reference sample in every block of two incomplete block designs. In the present study, we have combined the use of lattice design and the control plots together and investigating their effect under various soil variation conditions.

one check variety was used in this study. It can be extended to use 2 or more check varieties depending upon the design used. In the present setup, 2 check varieties can be used, the assignment of the check varieties can be shown in Table 6. From a practical point of view, the testing varieties must be better than or equal to the checks in order to be selected for promotion. To include checks in the lattice design, it has been demonstrated that it will not only improve the precision of the experiment but also guaranty the performance of the selected varieties be better than or equivalent to the checks.

The computer program for lattice design (S026) used in this study is available upon request. 
4. Reference

Briggs, K.G. and L. H. Shebeski. 1968. Implications concerning the frequency of control plots in wheat breeding nurseries. Canadian J. Plant Science 48:149-153.

Cochran, W. G. and G. M. Cox. 1957. Experimental design, 2nded. John Wiley \& Sons, Inc. New York.

Gacula, M.C. Jr. 1978. Analysis of incomplete block designs with reference samples in each block. J. Food Sci. $43: 1461$.

Johnson, I. J. and H. C. Murphy. 1943. Lattice and lattice square designs with oat uniformity data and in variety trials. J. of American Society of Agronomy. 35:291-305.

Kalamkar, R. J. 1932. Experimental error and the field-plot technique with potatoes. J. Agri. Sci. 22:373-385.

Kempton, R. A. and C.W. Howes. 1981. The use of neighbouring plot values in the analysis of variety trials. Appl. stat. $30: 59-70$.

Pritchard, F. J. 1916. The use of checks and repeated plantings in variety tests. J. Amer. Soc. Agron. 8 (2) : 65-81.

Rosielle A. A. 1980. Comparison of lattice designs, check plots, and moving means in wheat breeding trials. Euphytics 29: 129-133.

Statistical Research Section 1981. S026 : Lattice design. Research Program Service, Research Branch, Agriculture Canada.

Wiebe, G. A. 1935. Variation and correlation in grain yield among 1500 wheat nursery plots. J. Agr. Res. 50:331357 .

Yates, F. 1936. A new method of arranging variety trials involving a large number of varieties. J. Agr. Sci. 26: 424-455. 
Table 1. Error mean squares and coefficients of variation of soil fertility in map 1 and map 2 .

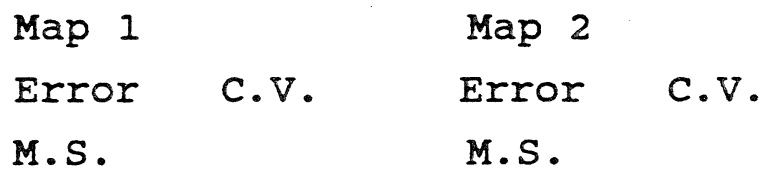

$\begin{array}{lllll}\text { Rep. 1 } & 0.8637 & 12.51 & 7.3257 & 41.31 \\ \text { Rep. 2 } & 0.8855 & 19.98 & 3.9876 & 27.30 \\ \text { Rep. 3 } & 0.7205 & 14.86 & 5.4029 & 31.97 \\ \text { Rep. 4 } & 1.4459 & 21.90 & 4.8354 & 33.93\end{array}$

Plot fertility range
$3.0-9.0$
$1.0-13.2$ 
Table 2. ANOVA of lattice design under 10 different soil variation structures in map 1 .

\begin{tabular}{|c|c|c|c|c|c|c|c|c|c|c|c|}
\hline \multirow{4}{*}{$\begin{array}{l}\text { source of } \\
\text { Variation }\end{array}$} & \multirow{4}{*}{ df } & \multicolumn{10}{|c|}{ Percent of soil to total variation } \\
\hline & & $100 \#$ & 90 & 80 & 70 & 60 & 50 & 40 & 30 & 20 & 10 \\
\hline & & & & & & & & & & & \\
\hline & & \multicolumn{10}{|c|}{ Mean squares } \\
\hline Replication & 3 & - & - & - & - & - & - & - & - & - & - \\
\hline varlety & 63 & 41.5 & 41.5 & 42.9 & 40.9 & 11.9 & 43.5 & 41.4 & 48.9 & 43.7 & 53.5 \\
\hline Block & 28 & 3.1 & 2.8 & 3.5 & 2.7 & $2 \cdot 6$ & 4.0 & $3 \cdot 6$ & $3 \cdot 4$ & 7.5 & 12.1 \\
\hline Error & 161 & 0.7 & 0.9 & 1.0 & 1.0 & 1.4 & 1.7 & 2.3 & 2.7 & 4.7 & 9.3 \\
\hline \multirow[t]{3}{*}{ R.R. C } & & 136 & 121 & 124 & 114 & 105 & 110 & 103 & 101 & 103 & 101 \\
\hline & & \multicolumn{10}{|c|}{ Mean squares of control plot only } \\
\hline & & 1.0 & 1.0 & 1.4 & 1.2 & 1.9 & 1.2 & 2.2 & 4.4 & 4.3 & 9.0 \\
\hline
\end{tabular}

- Value negligible.

* $100 * \sigma_{s}^{2} /\left(\sigma_{s}^{2}+\sigma_{e}^{2}\right)$, where $\sigma_{s}^{2}$ is soil variation and $\sigma^{2}$ is pure random error.

e R.R. Relativo efficiency. 
Table 3. ANOVA of lattice design under 10 different soil variation structures in map 1 after adjusting for control.

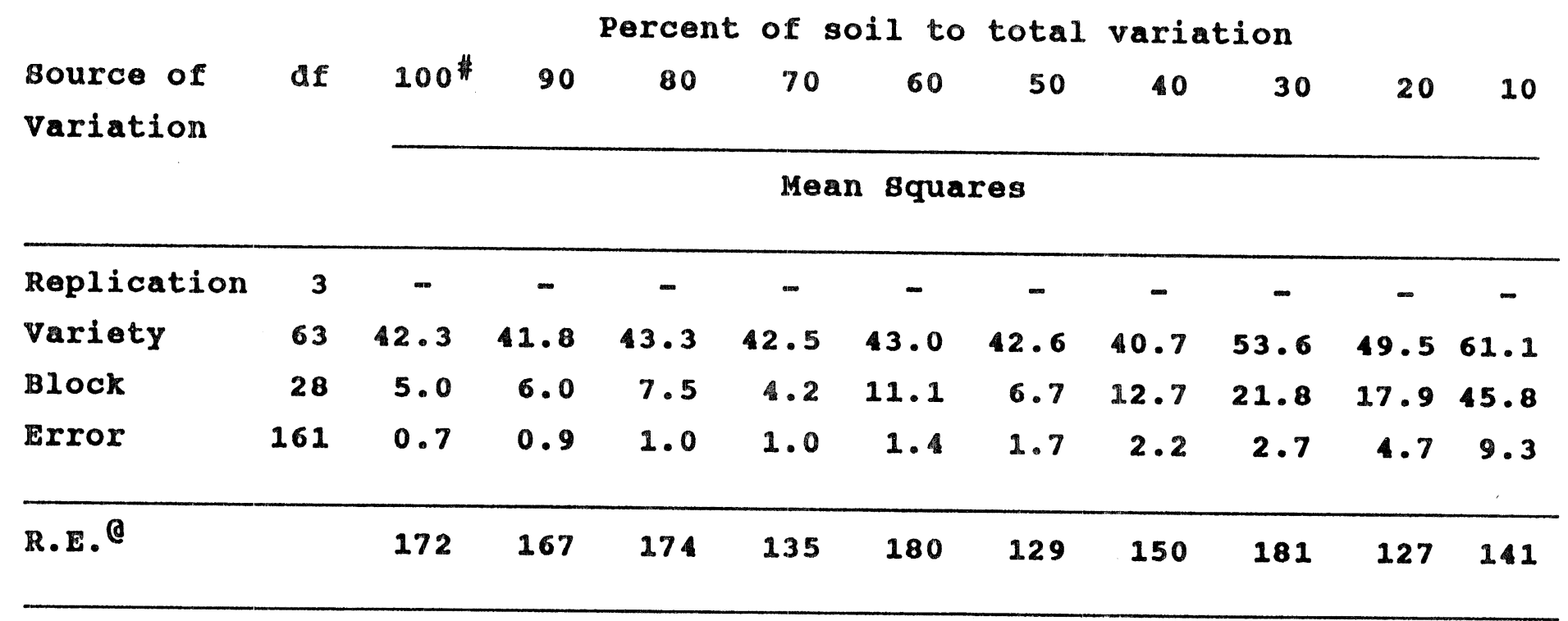

- Value negligible.

\# $100 * \sigma^{2} /\left(\sigma^{2} s+\sigma_{e}^{2}\right)$, where $\sigma^{2}$ is soil variation and $\sigma^{2}$ is pure random error.

e R.E. Relative efficiency. 
Table ANOVA of lattice design under 10 different soil variation structures in map 2 .

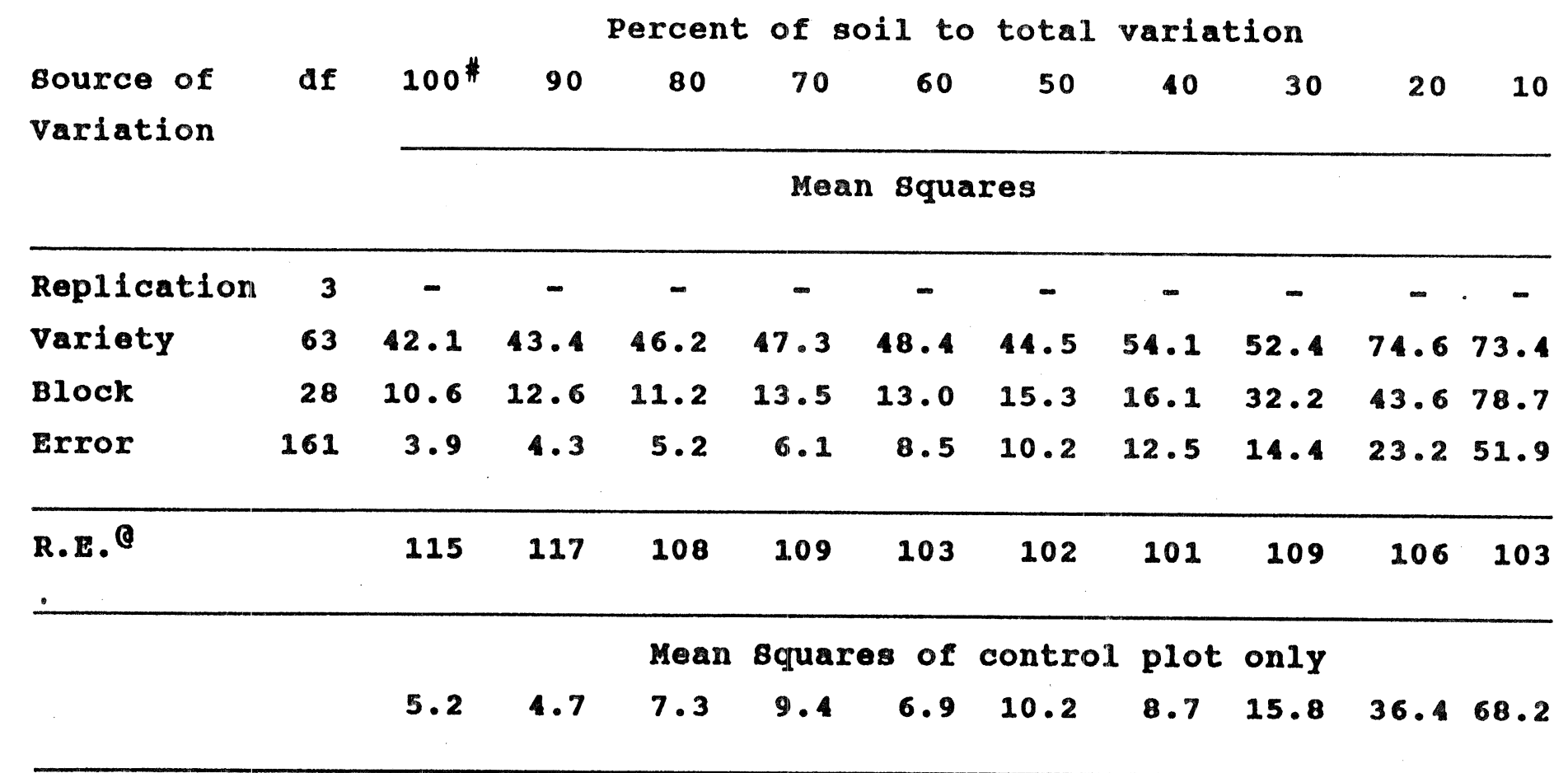

- Value negligible.

\# $100 * \sigma^{2} s /\left(\sigma^{2} s+\sigma_{e}^{2}\right)$, where $\sigma_{s}^{2}$ is soil variation and $\sigma^{2}$ is pure random error.

C R.E. Relative efficiency. 
Table 5. ANOVA of lattice design under 10 different soil variation structures in map 2 after adjusting for control.

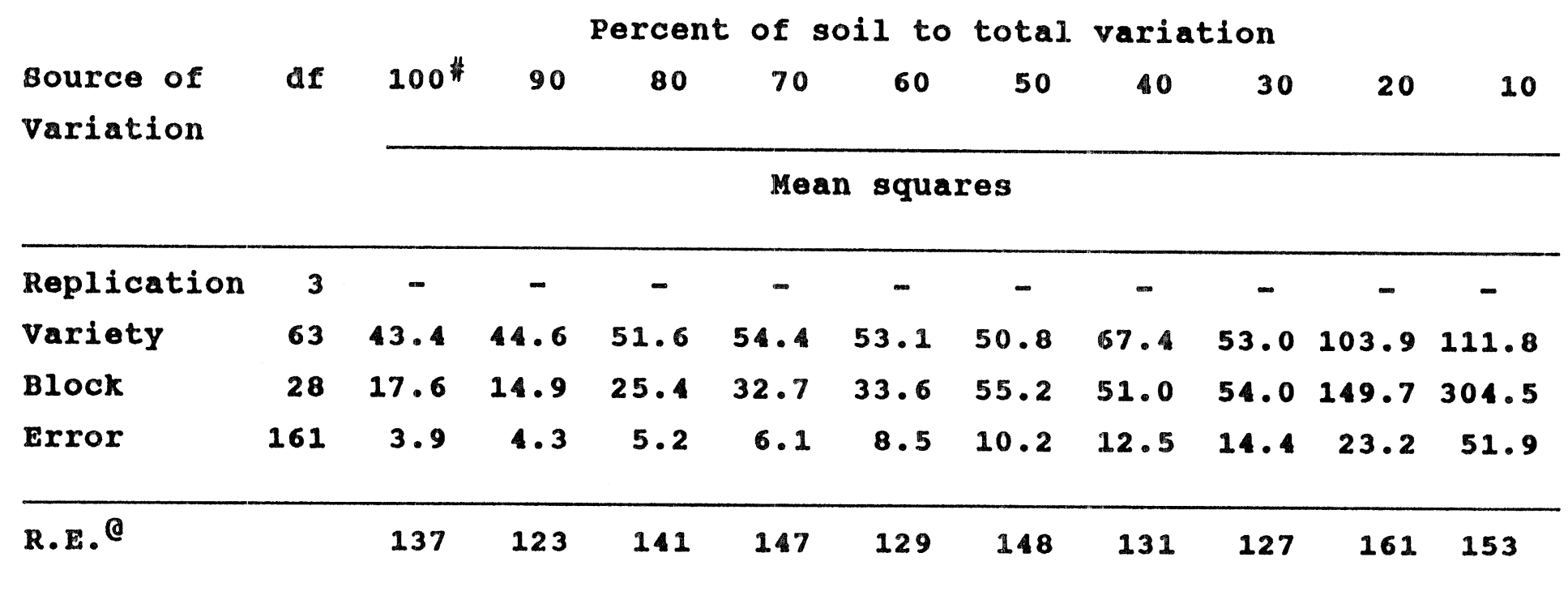

- Value negligible.

\# $100 * \sigma^{2} s /\left(\sigma^{2} s+\sigma_{e}^{2}\right)$, where $\sigma_{s}^{2}$ is soil variation and $\sigma^{2}$ is pure random error.

C R.E. Relative efficiency. 
Table 6. The setup of check variety for each block in an eight by eight lattice design.

$\begin{array}{rrrrrrrrr}\text { Block 1 } & 16 * & 9 & 12 & 15 & 10 & 14 & 11 & 13 \\ \text { Block } 2 & 30 & 29 & 32 * & 25 & 28 & 31 & 26 & 27 \\ \text { Block } 3 & 6 & 4 & 1 & 8 * & 3 & 5 & 2 & 7 \\ \text { Block } 4 & 35 & 39 & 34 & 38 & 36 & 40 * & 37 & 33 \\ \text { Block } 5 & 62 & 64 * & 57 & 59 & 60 & 61 & 58 & 63 \\ \text { Block } 6 & 41 & 45 & 47 & 42 & 44 & 46 & 43 & 48 * \\ \text { Block } 7 & 20 & 23 & 21 & 17 & 22 & 18 & 24 * & 19 \\ \text { Block } 8 & 53 & 55 & 50 & 51 & 56 * & 49 & 52 & 54\end{array}$

* One check variety

$\operatorname{Rep} 1 \quad \operatorname{Rep} 2 \operatorname{Rep} 3 \quad \operatorname{Rep} 4$

$\begin{array}{rllll}8 & \text { A } & \text { B } & \text { A } & \text { B } \\ 16 & \text { A } & \text { B } & \text { B } & \text { A } \\ 24 & \text { A } & \text { B } & \text { B } & \text { A } \\ 32 & \text { A } & \text { B } & \text { A } & \text { B } \\ 40 & \text { B } & \text { A } & \text { B } & \text { A } \\ 48 & \text { B } & \text { A } & \text { A } & \text { B } \\ 56 & \text { B } & \text { A } & \text { B } & \text { A } \\ 64 & \text { B } & \text { A } & \text { A } & \text { B }\end{array}$

Two check varieties: $A$ and $B$. 


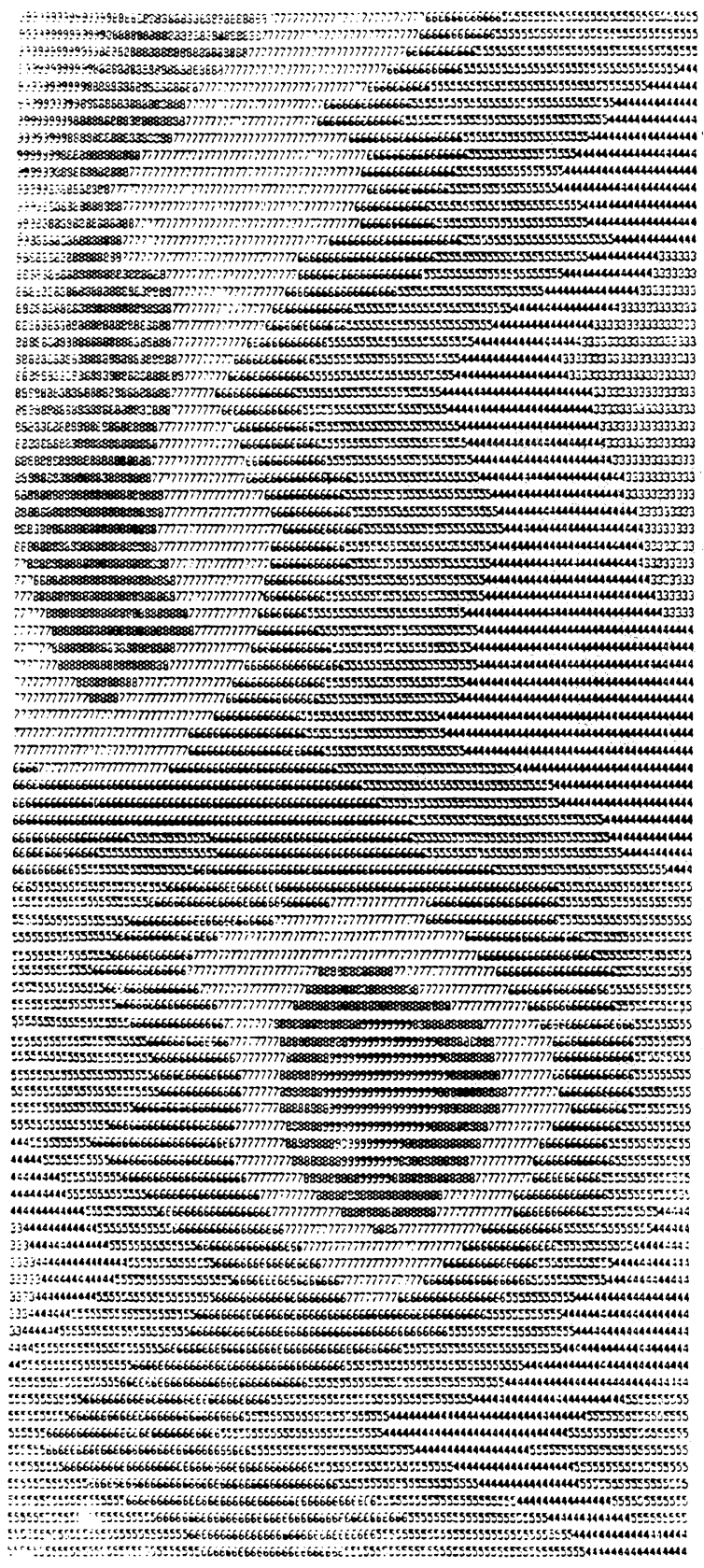

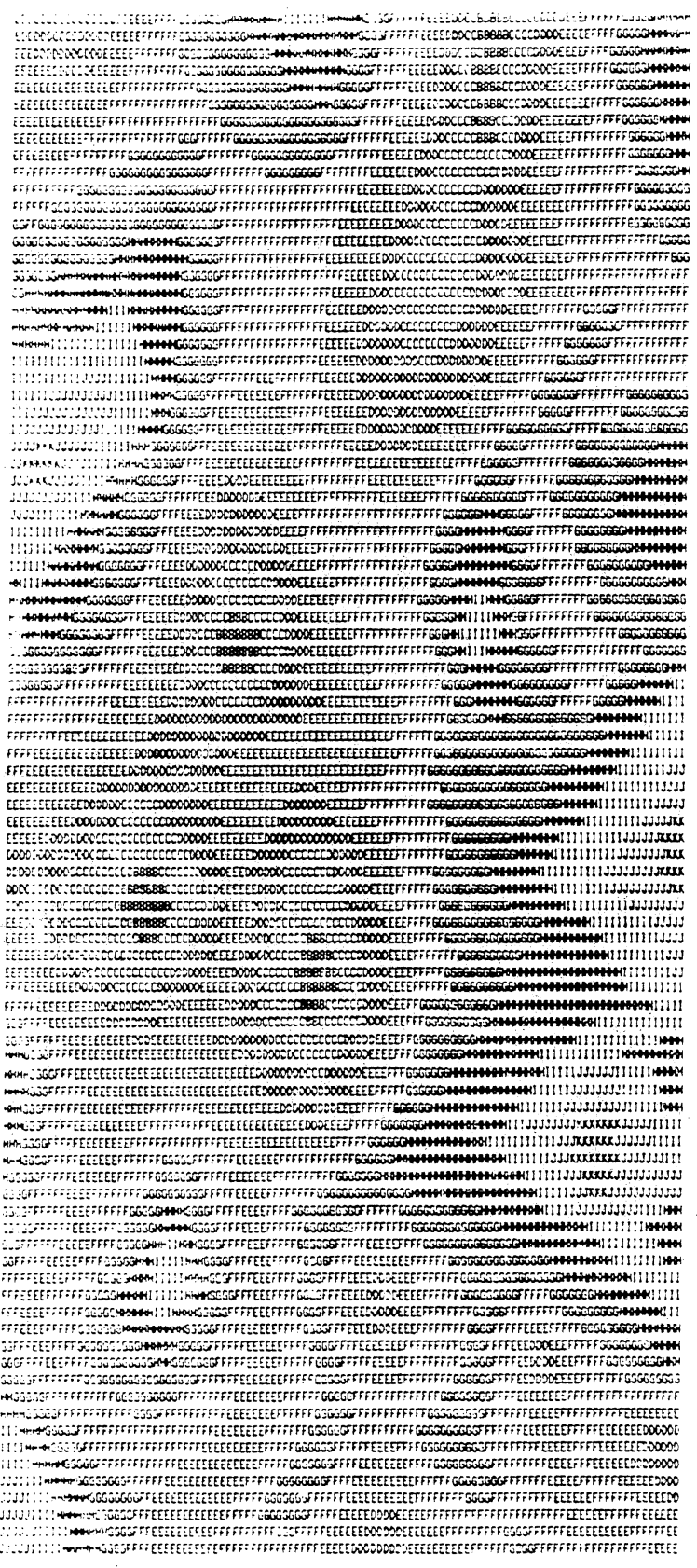

Map 1

Map 2

Figure 1 . Soil fertility maps 